\title{
In-cylinder Polycyclic Aromatic Hydrocarbons (PAHs) Sampled during Diesel Engine Combustion
}

\author{
Christopher C Ogbunuzor*, Paul R Hellier, Midhat Talibi, Nicos Ladommatos \\ Department of Mechanical Engineering, University College London, UK
}

6

\begin{abstract}
Polycyclic aromatic hydrocarbons (PAH) are potentially carcinogenic pollutants emitted by diesel engines, both in the gas-phase and adsorbed onto the surface of particulate matter (PM). There remains limited understanding of the complex and dynamic competing mechanisms of PAH formation, growth and oxidation in the gas-phase and their adsorption onto soot, and how these processes impact on the abundance and composition of exhaust PAH. Therefore, this paper presents analysis of gas and particulate samples taken from the cylinder and exhaust of a diesel engine during combustion of fossil diesel with the 16 US-EPA priority PAH species identified and quantified.

In-cylinder results showed that gas phase PAHs were more abundant than soot-bound PAHs in the engine cylinder. The in-cylinder PAHs included 2- to 6-ring PAHs, however, 6-ring PAHs were not observed in the soot samples collected from the engine exhaust. Levels of both PM and the total in-cylinder PAHs decreased following a peak at 10 CAD ATDC, but subsequently increased significantly during the late combustion phase. The $\mathrm{B}[\mathrm{a}] \mathrm{P}$ equivalence of $\mathrm{PM}$ in the engine cylinder increased during the period of early diffusion to late combustion phase, following an initial decrease during the period of premixed to early diffusion combustion.
\end{abstract}

Keywords : Polycyclic aromatic hydrocarbon (PAH), fossil diesel combustion, particulates toxicity, $P A H$ growth mechanisms, US-EPA priority PAH, gas phases PAH, soot-bound PAH, in-cylinder sampling, exhaust sampling 


\section{Introduction}

Internal combustion (IC) engines used in road transportation continue to be a major anthropogenic source of both greenhouse gas emissions and pollutants that impact on air quality (1) (2). Combustion processes in compression-ignition and spark-ignition engines produce and emit gaseous pollutants including NOx, CO, total hydrocarbons and also soot, the permissible levels of which are strictly regulated (1) (3) (4). Soot particles also carry substances through adsorption onto the particle surface, including polycyclic aromatic hydrocarbons (PAHs) which are known mutagens and are of immense concern because of their high toxicity to human health (5) (6) (7) (8) (9) (10) (11). Over 32 PAH species have been found in diesel engine emissions, but 16 of these species were selected by the US Environmental Protection Agency (US-EPA) as priority pollutants primarily on the basis of their higher toxicity potential, their possibility of human exposure and environmental occurrence, therefore, it is important to measure them. Seven of the 16 PAHs have been deemed possible human carcinogens and have been underscored in Table $S 1$ (see supporting information) (11) (12) (13). While many researchers have extensively studied the emission of particulate matter (PM) and the 16 PAH species prioritized by the US-EPA in the exhaust of a diesel engines fuelled with $100 \%$ fossil diesel (14) (15) (16) (17) (18) (19), very few studies have provided insights into the composition and abundance of these exhaust emissions by way of investigating PAH inside the engine cylinder during the course of combustion. An early study of fossil diesel combustion undertaken by Barbella R, Bertoli C, Ciajolo A, D'anna A (20) using incylinder samples reported that soot concentration and PAH fraction in weight per weight (\%wt/wt) increased after fuel injection to a peak at around 10 CAD ATDC (indicating increased soot formation rates) and decreased afterwards during the remainder of combustion (due to oxidation), in agreement with the findings of Malmborg VB, Eriksson AC, Shen M, Nilsson P, Gallo Y, Waldheim $B$, Martinsson J, Andersson O, Pagels J (21). PAH species present in the fossil diesel fuel were compared by Barbella R, Bertoli C, Ciajolo A, D'anna A with the PAH fraction of all samples collected from the cylinder and they were found to be identical, indicating that no combustion-formed PAH species were detected. The authors attributed this observation to the faster formation kinetics of these species relative to the temporal resolution of the sampling valve used (20).

Later experimental in-cylinder studies have instead utilised single-component fuels as a surrogate for diesel (22) (23), with the addition of an aromatic to replicate fossil diesel combustion. One such study by Narushima T, Morishima A, Moriwaki H, Kusaka J, Daisho Y (23) reported that during $n$-heptane combustion the level of in-cylinder gaseous cyclic compounds, including PAHs with less than five rings, was reduced as the air-fuel mixture became increasingly lean, due to oxidation. Wang X, Song C, Lv G, Song J, Li H, Li B (22) also found from in-cylinder studies that the addition of toluene to $n$-heptane promoted soot formation, reduced the total EPA PAH level, but increased the amounts of PAHs that were equal in size or larger than Phenanthrene (PHE) relative to that found during $n$-heptane combustion. Furthermore, Wang $\mathrm{X}$, Song $\mathrm{C}, \mathrm{Lv} \mathrm{G}$, Song J, $\mathrm{Li} \mathrm{H}$, Li B found that naphthalene (NAP) was the most abundant PAH present at all sampling times during the combustion of $n$-heptane and $n$-heptane-toluene blend, with three-ring PAHs, acenaphthene (ACN), acenaphthylene (ACNY), and fluorene (FLU) also present in significant quantities. Like Wang X, Song C, Lv G, Song J, Li H, Li B, Ciajolo A, D’Anna A, Barbella R, Bertoli $\mathrm{C}$ (24) also studied the influence of fuel aromaticity on in-cylinder PAHs, but by the addition of aMethylnaphthalene to $n$-tetradecane. While the addition of aromatics to the diesel surrogate fuel was found to promote soot formation in both studies, Wang X, Song C, Lv G, Song J, Li H, Li B observed a decrease in the total mass of in-cylinder PAHs in contrast to an increase observed by Ciajolo A, D'Anna A, Barbella R, Bertoli C. Of these previous in-cylinder studies, only two utilised fossil diesel, and the discordant results seen in the utilisation of diesel surrogates makes further investigation of fossil diesel itself imperative, because fossil diesel fuel is known to contain various hydrocarbons including paraffins, olefins, cycloparaffins and aromatics (25) which are absent in single-component surrogates and can therefore significantly impact on the PAH process. In the study by Barbella R, Bertoli C, Ciajolo A, D'anna A, quantitative analysis of individual PAH species was not undertaken, and so changing levels of total and individual PAH species during combustion was not investigated. The authors utilized ice traps to condense heavy hydrocarbons during 
samples collection, and gaseous PAH species might have condensed during this process, thus making it difficult to ascertain the separate proportions in the gaseous and solid PAH phases. The diesel fuel utilised by Barbella R, Bertoli C, Ciajolo A, D'anna A contained an excessively high PAH content (33.6\%wt), which is no longer representative of the PAH content of modern diesel fuel, now typically below $5 \%(26)$. In the study undertaken by Malmborg VB, Eriksson AC, Shen $M$, Nilsson P, Gallo Y, Waldheim B, Martinsson J, Andersson O, Pagels J, though quantitative, only soot-bound PAH, comprised majorly of 4- to 6-ring PAH species, were investigated.

PAHs are known precursors to formation of soot particles in engines following pyrolysis of injected fuel (27), and their levels during combustion are influenced by competing and dynamic mechanisms of formation and consumption, either through growth to larger species or oxidation. The evolution of gaseous and soot-bound in-cylinder PAHs during fossil diesel combustion in the cylinders of modern direct injection diesel engines and their relationship to the PAH concentrations in the exhaust are still not well understood. There has not previously been such a complete study of analysis of PAHs in both gas and particulate phases. In this paper, analysis of PM and PAHs in samples of gas and PM extracted from the engine cylinder and exhaust gases is presented, with individual PAH levels in the gas- and soot-bound phases quantified. Further, the impact of the PAH levels on the PAH toxicity (B(a)P equivalence) is quantified and discussed.

\section{Experimental Approach}

\subsection{Experimental Setup}

Please note that Table S 1 - Table S 6 and Figure S 1 - Figure S 9 are shown in the supporting information. Figure $\mathrm{S} 1$ shows a schematic diagram of the experimental facility, utilised for all the engine tests reported in this study, which was comprised of a direct injection compression-ignition research engine (see Table $S 2$ ), a common fuel rail system which supplied diesel to the engine at the injection pressure, and particulate matter and gaseous PAH collection systems (filter holder housing and resin holder housing) located $0.65 \mathrm{~m}$ from the exhaust valves. The particulate collection system comprised separate filter and resin holder housings, installed in series, into which the filter and XAD-2 resin were housed, respectively. A vacuum pump drew sample gas through the filter and resin and a gas meter at the exit of the vacuum pump measured the cumulative flow of sample gas. A fast-acting in-cylinder gas sampling valve (IGSV), which was developed and extensively tested by Talibi M, Hellier P, Balachandran R, Ladommatos N (28) to determine consistency of operation and define various operational parameters, including valve opening and closing instants, consistency of sampling windows, penetration of poppet valve into the in-cylinder charge well beyond the boundary layer etc, enabled the extraction and sampling of the contents (PM and combustion-generated gases) present in the combustion chamber (further details of is the IGSV are presented in Section 6.3 of supporting information). In-cylinder sampling was undertaken at four points during the combustion cycle namely 10 CAD ATDC (post premixed combustion dominated), 25 CAD ATDC (diffusion combustion dominated), 40 CAD ATDC (late diffusion combustion) and 55 CAD ATDC (late combustion). In order to collect sufficient gas and particulate sample for analysis, the sampling valve was operated once every three engine cycles until sufficient large samples accumulated for subsequent analysis. The filter holder housing, resin holder housing and all the $1 / 4$ " stainless-steel sampling pipes to both the IGSV and exhaust pipe were heated by insulated PID-controlled (Proportional Integral Derivative) electric tape heaters maintained at $250{ }^{\circ} \mathrm{C}$ to prevent condensation of water vapour and gaseous hydrocarbons. No exhaust after-treatment devices were utilised, and the experiments were conducted without exhaust gas recirculation (EGR). 


\subsection{Engine Test Procedure and Conditions}

For the collection of in-cylinder and exhaust PM, glass microfibre filter papers were chosen due to the absence of PAH in the filter material, heat resistance properties, wide-spread use in past studies, and recommended use in Method TO-13A provided by the US Environmental Protection Agency (11) (29) (30) (31) (32) (33). Fisher Scientific UK brand glass microfibre filters $\left(\varnothing=70 \mathrm{~mm}, 0.7 \mu \mathrm{m}\right.$ pore size, $75 \mathrm{~g} / \mathrm{m}^{2}$ mass, $310 \mathrm{~s}$ filtration speed) were used during all engine tests. To prevent the filter from tearing, breaking or deteriorating during sampling as a result of the engine exhaust flow and pressure pulsations, it was sandwiched between two fine, stainlesssteel 316 woven wire meshes (aperture $=0.026 \mathrm{~mm}, 0.025 \mathrm{~mm}$ wire diameter ( TheMeshCompany U.K) cut to the same diameter as the filter. Both halves of the filter holder firmly gripped the sandwiched filter, thus securing it in place for the duration of sampling. See Section 6.4 of supporting information for further details of the engine warm-up and sampling procedure.

The engine operating conditions for all tests are as follows:

- Engine load (IMEP): 7 bar

- Sample collection duration: 15 mins

- Start of injection: 8.8 CAD BTDC

- End of injection: 2.1 CAD BTDC
- Start of combustion: TDC

- Injection pressure: 450 bar

- Engine speed: $1200 \mathrm{rpm}$

- Injection duration: $925 \mu \mathrm{s}(<6.7$ CAD) Table 1 shows the in-cylinder sampling timings during combustion, the duration of sampling, the in-cylinder pressure, and the total free volume of gas sampled and measured under atmospheric conditions using a gas meter at each of the in-cylinder sampling timings. Sampling timings were chosen to encompass the whole of post premixed combustion. A vacuum pump operating at a flow rate of $43 \mathrm{~L} / \mathrm{min}$ was used to sample from the engine exhaust while the sampling valve gas flow rate from the engine combustion chamber was significantly lower at $1-2 \mathrm{~L} / \mathrm{min}$.

Table 1: The in-cylinder sampling timings, duration of sampling windows, in-cylinder gas pressure and sample volume collected for each of the in-cylinder sampling timings

\begin{tabular}{|c|c|c|c|c|}
\hline $\begin{array}{c}\text { In-cylinder } \\
\text { sampling timings } \\
\text { (midway of } \\
\text { sampling window }\end{array}$ & $\begin{array}{c}\text { IGSV opening } \\
\text { window (CAD) }\end{array}$ & $\begin{array}{c}\text { In-cylinder } \\
\text { pressure during } \\
\text { sampling window } \\
\text { (bar) }\end{array}$ & $\begin{array}{c}\text { Global in- } \\
\text { cylinder } \\
\text { temperature } \\
(\mathrm{K})\end{array}$ & $\begin{array}{c}\text { Total sample } \\
\text { volume (L) }\end{array}$ \\
\hline 10 CAD ATDC & 6 & 61.8 & 1222.1 & 17.95 \\
\hline 25 CAD ATDC & 10 & 42.7 & 1482.5 & 27.45 \\
\hline 40 CAD ATDC & 15 & 22.9 & 1403.1 & 19.35 \\
\hline 55 CAD ATDC & 15 & 13.3 & 1277.6 & 12.2 \\
\hline Exhaust & - & - & - & 270 \\
\hline
\end{tabular}

\subsection{Fossil diesel properties}

Table $\mathrm{S} 3$ shows the fuel properties of the fossil diesel utilised in all engine tests reported in this study. To identify the individual EPA PAH species present in liquid fossil diesel prior to combustion, the total PAH content of fossil diesel was also speciated, and the results are shown in this table.

\subsection{Soot-bound and gas phase PAH analysis procedure}

All sandwiched filters utilised for collecting particulate matter were desiccated for 12 hours (including supporting mesh) to remove any water accrued due to sampling so that any change in mass of the filter was not attributable to moisture content. The filters were subsequently weighed to determine their new mass (sandwiched filter + particulate), and the gravimetric mass of particulate matter collected was the difference between this new mass and that recorded prior to sampling. 
After the mass of particulate matter collected was determined, PAH species were extracted using dichloromethane solvent from all used sandwiched filters and from the XAD-2 resin, referred to as soot-bound PAHs and gas-phase PAHs respectively throughout this study. The extraction used an accelerated solvent extraction (ASE) system previously optimised by Dandajeh HA, Ladommatos N, Hellier P, Eveleigh A (30) (34) and further described in Section 6.6 (see supporting information). The volume of the extract (solvent $+\mathrm{PAH}$ ) in the collection bottle at the end of one extraction process was typically between $20-30 \mathrm{ml}$. The PAH extraction method was repeated three times for each engine sample to ensure complete recovery of PAH species, and the three extracts from the three repeat extraction processes of the same engine sample were mixed together. Table S 4 shows the optimised ASE extraction conditions utilised for PAH recovery from all samples collected from the engine. Further steps on the concentration and preparations of ASE extracts are also described in Section 6.6.

\subsection{Gas Chromatography-Mass Spectrometer (GCMS) Setup}

Table $S 5$ (supporting section) summarizes the operating parameters of the gas chromatograph-mass spectrometer (GCMS) instrument utilized for identifying and quantifying PAH species. Similar to several past studies (14) (35) (22) (11) (32) (36), the GCMS was utilised in SIM mode.

\subsection{Quantification of PAH present in the ASE extracts of all engine samples}

Each deuterated PAH species in the internal standard (IS) was assigned to one or more of the 16 EPA PAH species, as recommended by the EPA (29) and shown in Table S 6. Calibration curves (ratio of PAH concentration to that of assigned IS versus ratio of peak areas of PAH to IS) were plotted for each PAH species from which equations of line of best fit were generated. The concentrations of each PAH species in the engine samples extract were determined using its equation of line of best fit, ratio of peak areas recorded during GCMS run and the final concentration of the assigned internal standard species $(0.89 \mathrm{ppm})$. B[a]P concentration was calculated, using Eqn. 1, as the sum of the products of each PAH species' $\mathrm{B}$ [a]P toxicity equivalent factor (TEF) (30) and its concentration, for all 16 PAHs quantified. The TEF indicates PAH toxicity relative to $\mathrm{B}[\mathrm{a}] \mathrm{P}$ and values were taken from the work of Nisbet and LaGoy (37).

$$
B[a] P_{\text {equivalence }}=\sum_{i=1}^{16}(T E F \times P A H \text { concentration })
$$


This results of this study are presented in this section while the discussion of the results are 229 presented later in Section 4.
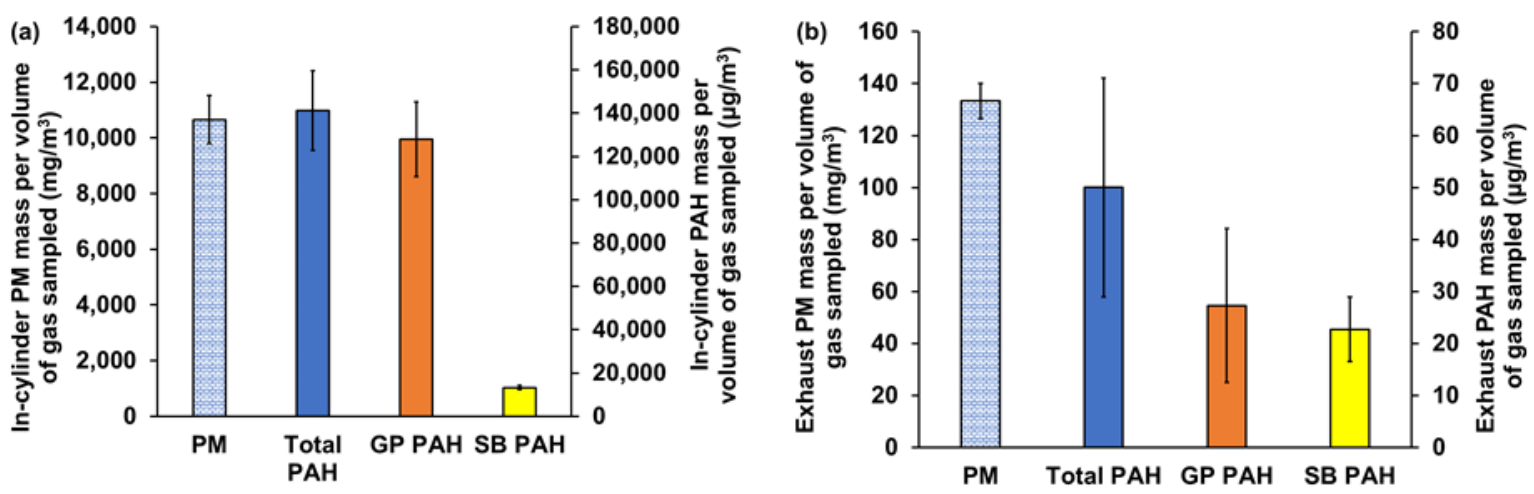

Figure 1: PM, total PAH, gas-phase and soot-bound PAH concentrations present in (a) the engine cylinder immediately following the premixed combustion phase at 10 CAD ATDC (b) the exhaust gas

Figure 1a shows the PM concentration, total PAH concentration and, gas phase PAH and soot-

bound PAH concentrations sampled from the engine cylinder during the premixed combustion phase at 10 CAD ATDC (combustion commenced at TDC) while Figure 1 b shows those in the exhaust gas. The concentrations of PM and PAH in the engine cylinder and in the exhaust can be seen in Figure $1 a$ and $b$ respectively. The error bars shown in Figure $1 a$ and $b$, and where shown in subsequent figures throughout this paper, are plus and minus one standard deviation from the mean of the values measured; three repeat experiments were undertaken for the measurement of PM mass collected with two filters further analysed for determination of PAH concentrations. Sources of variability include cycle to cycle variability in the actual concentration present in the engine due to the turbulent and complex nature of combustion, variability in solvent extraction
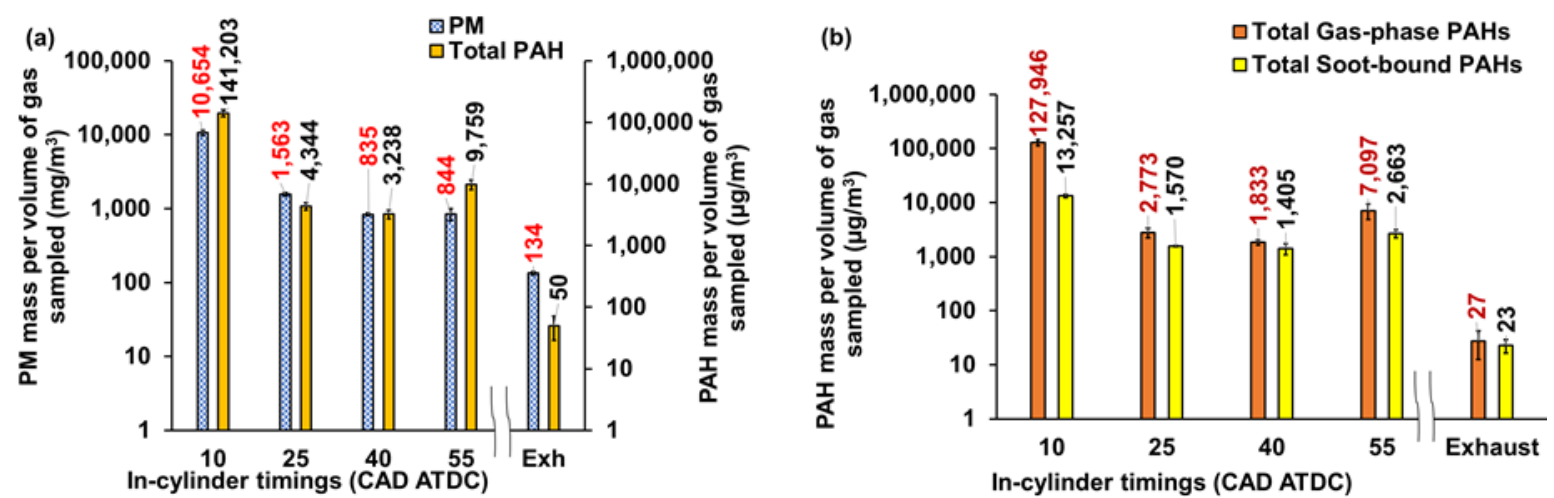

process from PM samples, variability in preparing the calibration standard for GCMS runs.

Figure 2: (a) Masses of particulate and total PAH per volume of gas sampled at 10, 25, 40, 55 (all in CAD ATDC) and exhaust (Exh) (b) Total gas-phase and soot-bound PAH measured at 10, 25, 40, 55 CAD ATDC and the exhaust.

Figure Za shows the mass of PM and total PAH (gas phase + soot bound phase) per volume of gas measured in the in-cylinder gas samples extracted during combustion and from the exhaust gas. Figure $2 b$ shows the total gas phase and total soot bound PAH species on a mass per volume of gas basis at the four in-cylinder sampling timings and from the exhaust gas. The PM and PAH profiles during combustion can be seen in Figure $2 a$ while the gas-phase and soot-bound PAH compositions are shown in Figure $2 \underline{b}$. 

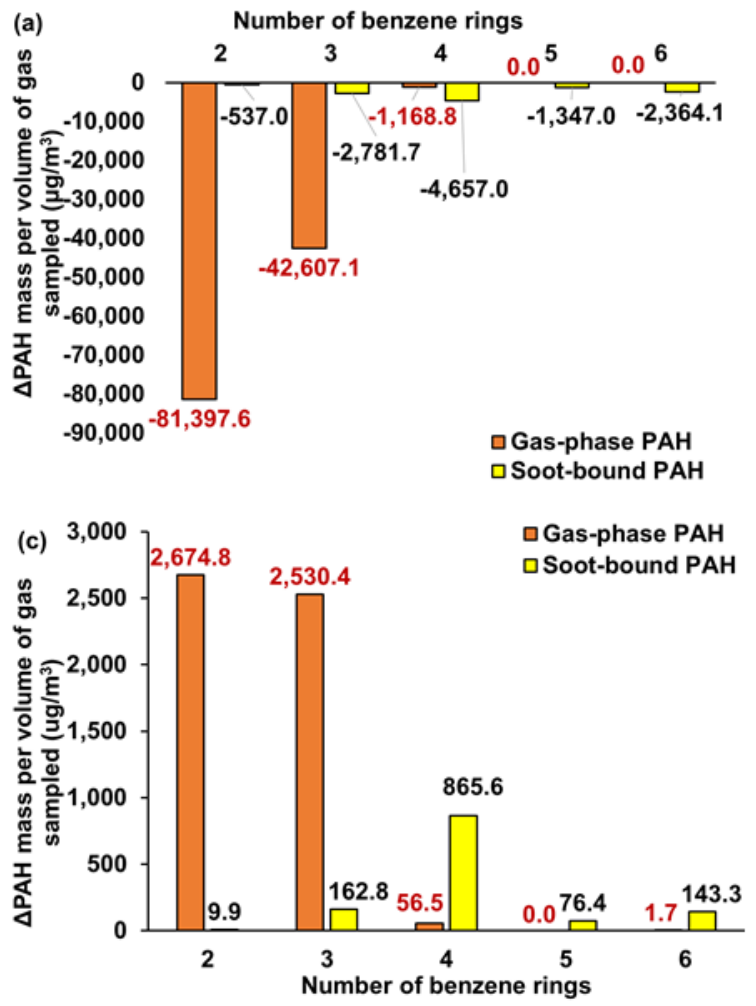
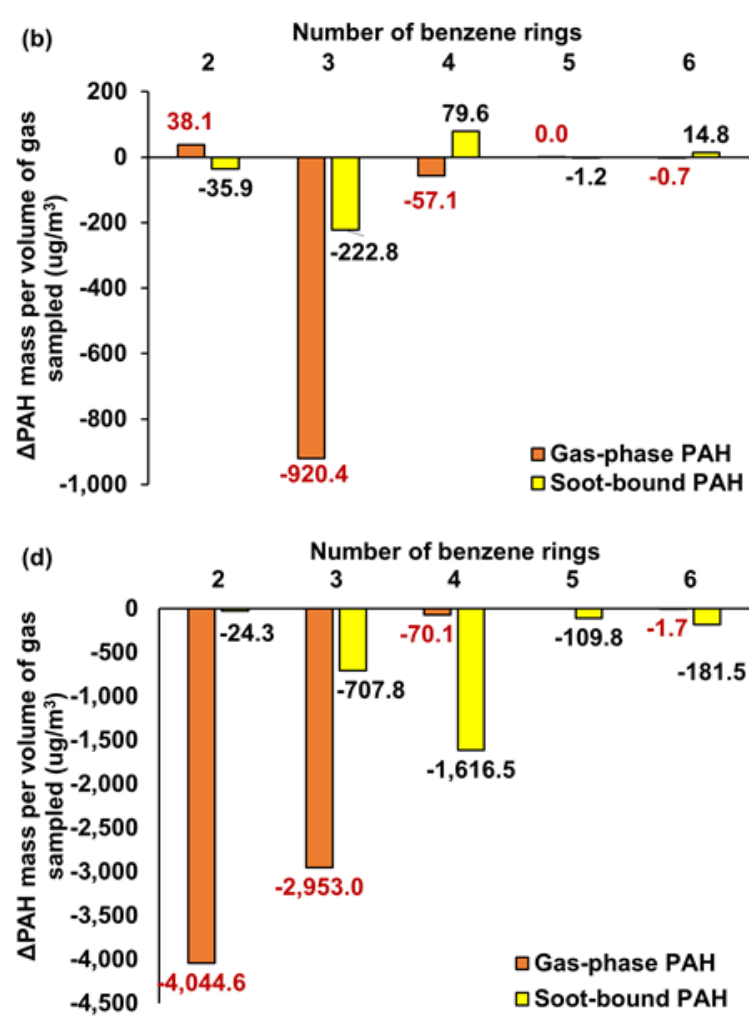

Figure 3: Change in the masses per volume of gas (concentration) of gas-phase and soot-bound 2- to 6-ring PAH during combustion (a)10 - 25 CAD ATDC (b) 25 - 40 CAD ATDC (c) 40 - 55 CAD ATDC (d) 55 CAD ATDC - Exhaust

Figure $3 a-d$ show the changes in the total concentrations of gas phase and soot bound 2 to 6 ring PAHs during combustion from 10 CAD ATDC through the other in-cylinder sampling timings to the exhaust. The changes from one sampling timing to the next through to the exhaust in the concentrations of 2- to 6-ring PAH present in the gas- and soot-bound phases can be seen in Figure 3a-d. 

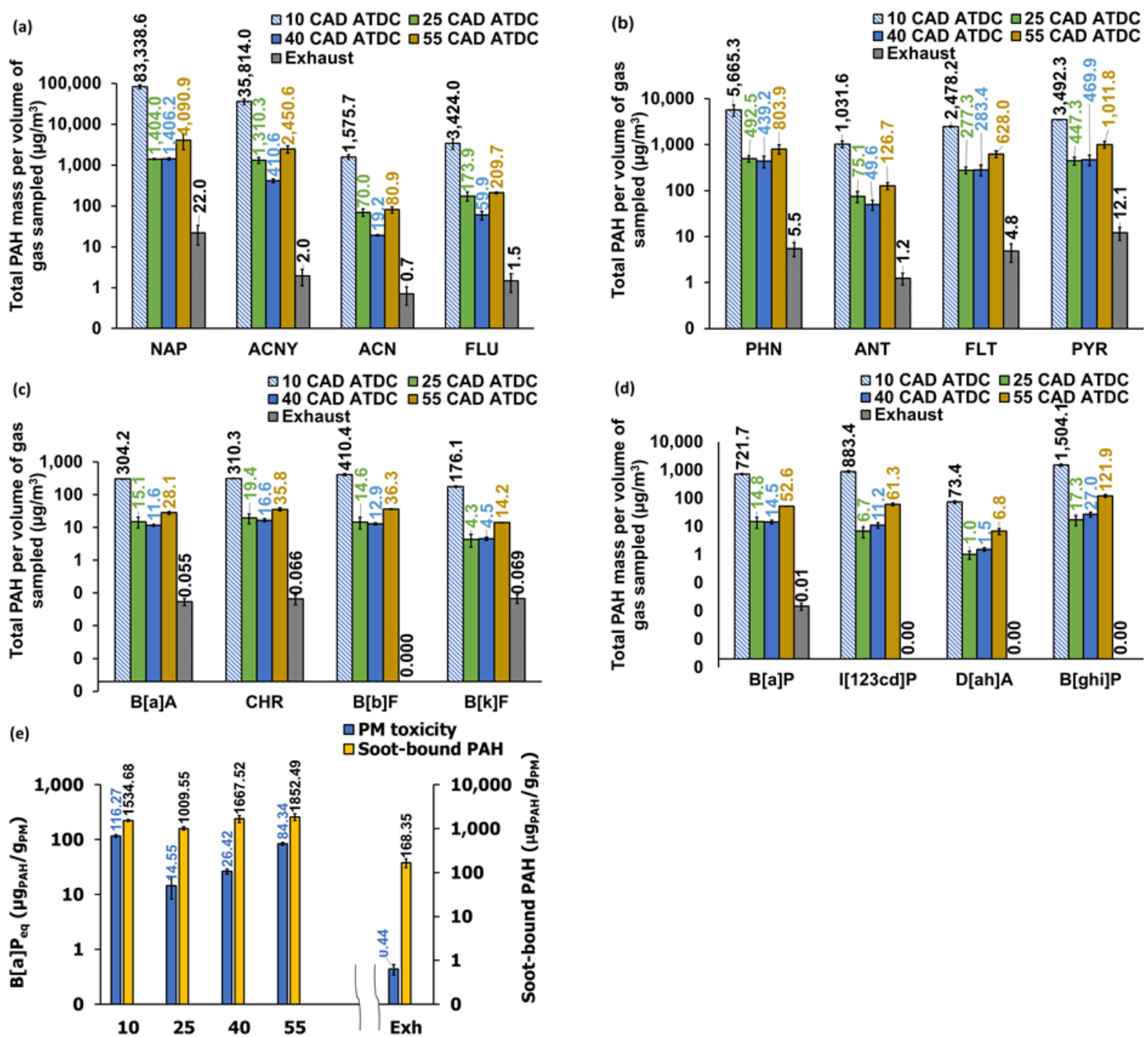

In-cylinder sampling points (CAD ATDC)

Figure 4: Total measured amounts (gas phase + soot-bound) of each of the 16 EPA priority PAH species at each of the sampling points from 10 CAD to 55 CAD ATDC (a) naphthalene, acenaphthylene, acenaphthene and fluorene (b) phenanthrene, anthracene, fluoranthene and pyrene (c) benzo[a]anthracene, chrysene, benzo[b]fluoranthene, benzo[k]fluoranthene (d) benzo[a]pyrene, indeno[123cd]pyrene, dibenz[ah]anthracene and benzo[ghi]perylene (e) PM toxicity (B[a]P equivalence) and total soot-bound EPA PAH levels of particulate matter collected during combustion at 10 CAD, 25 CAD, 40 CAD, 55 CAD ATDC and exhaust

Figure $4 a-d$ shows the abundance of each of the 16 EPA priority PAH species present in the engine cylinder at the sampling timings. Figure 40 shows the level of PM toxicity and soot bound PAH present during combustion at the timings of 10, 25, 10, and 55 CAD ATDC, and exhaust. The concentration of each of the 16 EPA priority PAH species during combustion and PM toxicity can be seen in Figure 4a-d and Figure 4e respectively. It can be seen from Figure 4a-d that all of the 16 EPA priority PAH species were found at varying quantities during diesel combustion. 


\section{Discussion}

\subsection{In-cylinder PM and PAH}

\subsubsection{Abundance of PM, Total PAH, gas-phase and soot-bound PAH concentration during premixed combustion}

Firstly, it is immediately apparent in Figure 1 a that in-cylinder PM and PAH concentrations during premixed combustion are significantly higher relative to those found in the exhaust (Figure 1b). Previous studies by Wang X, Song C, Lv G, Song J, Li H, Li B (22), Barbella R, Bertoli C, Ciajolo A, D'anna A (20), and Malmborg VB, Eriksson AC, Shen M, Nilsson P, Gallo Y, Waldheim B, Martinsson J, Andersson O, Pagels J (21) all found in-cylinder PM concentrations at around 10 CAD ATDC to be significantly greater than those in the exhaust. To understand why the in-cylinder PM concentration is significantly higher at 10 CAD ATDC, Dec's conceptual model of diesel combustion (38) proposed that soot is formed in the fuel-rich core of the leading portion of the fuel/air jet during the combustion of premixed fuel. Furthermore, as $60 \%$ of injected fuel was still unburnt during this time and since the sampling zone is from within the fuel spray (Figure S 2a), significant PM can be expected and attributable to the presence of fuel-rich areas and high temperatures. As the combustion chamber volume increases during the expansion stroke, intense turbulent mixing with in-cylinder air dilutes the rich burning zones, oxidising PM and eventually reducing its concentration to the exhaust level.

It is strikingly apparent from Figure 1a that the total in-cylinder PAH concentration significantly exceeds that measured in the exhaust (Figure 1b) (detailed exhaust measurements are available in Section 6.10 of supporting information) and this finding is also consistent with previous studies by Barbella R, Bertoli C, Ciajolo A, D'anna A (20) and Wang X, Song C, Lv G, Song J, Li H, Li B (22). PAHs are known soot precursors and so given the likely presence of conditions suitable for PM formation and the elevated levels of PM present at 10 CAD ATDC relative to the exhaust, an elevated level of PAH might also be expected (Figure 1a). It is immediately clear from Figure 1a that the total in-cylinder PAH concentration is dominated by gaseous PAH $(90.6 \%)$, which was also observed in the case of the exhaust emission (Figure 1b) but with a much-reduced disparity between levels of gas phase relative to soot-bound PAH. Richter and Howard (1) proposed that the inception of particulate matter begins from heavy PAH molecules, which are typically sootbound PAHs. It is tentatively suggested that some of the in-cylinder PM concentration measured at 10 CAD ATDC may be as a result of the consumption of soot-bound PAH, and thus muchreduced concentrations relative to the gas phase $\mathrm{PAH}$ levels at this time. Interestingly, it can be seen in Figure S 6 that 6-ring PAH were detected in the soot-bound phase, which were not detected in either the exhaust PAH emission (Figure S 4) or in the reference fossil diesel fuel itself. Additionally, as was seen in the case of the exhaust PAH emission, as the number of benzene rings increases, PAH become more abundant in the soot-bound phase, with 5- and 6-ring species detected only in this phase, potentially suggesting that PAH growth continues after adsorption onto soot particles. The computational study of Indarto A, Ghigo G, Maranzana A, Tonachini G on PAH formation following adsorption onto soot particles suggests growth to larger PAH species via cyclisation to be dominant (39). It is also clearly seen from Figure S 6 that the total in-cylinder PAH concentration (Figure $1 \mathrm{a}$ ) is dominated by 2 and 3-ring PAH species with a significantly greater proportion of these PAH species detected in the gaseous phase. It is suggested that the significant levels of gaseous 2 and 3-ring PAHs could have resulted from the vapourised unburnt fuel likely present at this time. For clarity, 5 and 6-ring PAHs were not detected in the gaseous phase and therefore the total PAH concentration for these species equated to their soot-bound concentration. Each of the 16 EPA PAH species was also quantified at 10 CAD ATDC, shown in Figure S 7a-d (supporting information) and discussed . 
4.1.2. Abundance of $P M$, total $P A H$, gas-phase and soot-bound PAH concentrations from premixed combustion to exhaust

The level of PM present at any time during combustion represents a net amount due to competing combustion processes of formation and oxidation. Figure $2 a$ shows that significantly higher levels of both PM and total PAH are present at 10 CAD ATDC than at any other sampling point, and it also indicates PM levels present to have dropped by a factor of 7 between 10 CAD ATDC and the second sampling point of 25 CAD ATDC, in agreement with the findings of Duggal VK, Priede T, Khan IM (40). Between the two sampling timings of 10 and 25 ATDC CAD, combustion was predominantly diffusion-controlled (Figure $S 3 a$ )-, during which high rates of PM oxidation can be expected (21). Malmborg VB, Eriksson AC, Shen M, Nilsson P, Gallo Y, Waldheim $\mathrm{B}$, Martinsson J, Andersson O, Pagels J. investigated levels of in-cylinder soot and PAH in a diesel engine equipped with a fast gas sampling valve, at an engine speed of $1200 \mathrm{rpm}$, and also observed a significant drop in the levels of both soot and PAH between 10 CAD and 20 CAD ATDC. Li Z, Song C, Song J, Lv G, Dong S, Zhao Z. (41) investigated the variation in the size of in-cylinder soot particles during diesel combustion, and observed soot particle size to increase up to a maximum during the early diffusion combustion followed by a decrease. The subsequent decrease in particle size was attributed primarily to high soot oxidation rates and a decrease in the net amount of soot formed as a result of high temperature conditions during the early diffusion combustion phase. The sharp decline in PM between 10 CAD ATDC and 25 CAD ATDC (Figure 2a) is likely to be attributable to a combination of the following four reasons: a reduction in fuel-rich zones within the in-cylinder charge as fuel continued to be burnt; an increase in oxidation rates during this period due to increasing in-cylinder temperature (Figure $S 3 \mathrm{~b}$ ); fuel air mixing promoted by in-cylinder air motion and turbulence; and lastly in-cylinder large-scale swirl motion which could have moved fuel-rich areas away from the sampling zone.

As combustion proceeded beyond 25 CAD ATDC, Figure 2a shows that in-cylinder PM continued to decrease approximately linearly, reaching a minimum in the exhaust, most likely due to continued soot oxidation and, to a lesser extent, reduced particle formation. The reduction in PM levels during the course of combustion is in agreement with an early optical study utilizing the two-colour method (42). Dec (43) observed that the emergence of PAH species coincided with the disappearance of fuel vapour, indicating fuel pyrolysis and synthesis to have occurred. Hiroyasu $\mathrm{H}$, Arai M, Nakanishi K (44) observed that as soot concentration increased, oxygen concentration decreased (and vice versa when oxygen concentration increased due to air entrainment). At the location of maximum soot, the oxygen concentration was found to be minimum, and in the area where soot concentration increased, liquid fuel evaporated. The similar levels of PM measured at 40 CAD and 55 CAD ATDC, given the presence of in-cylinder swirl, could indicate attainment of homogenous in-cylinder conditions. Talibi M, Hellier P, Balachandran R, Ladommatos N (28) observed that the levels of $\mathrm{NOx}$ present in the engine cylinder at 40 CAD ATDC were approximately the same when in-cylinder sampling occurred, first, from within a fuel spray and then between sprays, which suggests near-homogenous in-cylinder conditions during the later stages of diesel combustion (45). Considering PAHs now, Figure $2 \mathrm{~b}$ shows similar overall trends as those for PM. It can be seen in Figure $2 b$ that a peak in the total mass of PAH occurs at 10 CAD ATDC, which is in agreement with the observed peak level of PM at this time, and likely to have arisen as a result of an expected increase in the rate of fuel pyrolysis following significant heat release during the premixed combustion phase. The significant decline in PAH mass, observed at 25 CAD ATDC relative to 10 CAD ATDC (Figure 2a) could be attributed to the same reasons discussed earlier, in the case of PM. The slight decrease in the total PAH mass observed at 40 CAD relative to 25 CAD ATDC could be attributable to the continued significant oxidation rates present due to high global in-cylinder temperatures (Table 1). At 55 CAD ATDC, Figure 2a shows a significant rise in the total in-cylinder PAH mass to around three-times the value observed at 40 CAD ATDC. This rise in PAH mass could be attributable to an accumulation of new PAH species formed from the pyrolysis of fuel during this interval. Accumulation of newly-formed PAH species can occur due to a combination of decreasing oxidation and soot formation rates as in-cylinder temperature further decreases. Malmborg VB, Eriksson AC, Shen M, Nilsson P, Gallo Y, Waldheim B, Martinsson J, Andersson $\mathrm{O}$, Pagels $\mathrm{J}$ found an increase in in-cylinder PAH with the utilization of exhaust gas 
recirculation (EGR), which they attributed to $\mathrm{PAH}$ accumulation due to a decrease in soot formation rates as a result of decreased in-cylinder flame temperatures with EGR. It is also possible that the increased PAH mass at 55 CAD ATDC is due to in-cylinder air motion and swirl changing the relative composition of the fuel spray in the sampling zone. Barbella R, Bertoli C, Ciajolo A, D'anna A (46) observed an increase in heavy hydrocarbon concentration in the later stage of the combustion, and in further studies (20), they also observed an increasing trend in percent weight of total PAH species when in-cylinder gas was sampled from the edge of the fuel spray in the later stages of combustion, despite a trend of decreasing PAH earlier in the course of combustion. Also readily apparent from Figure $2 a$ is the significantly lower exhaust PAH levels relative to that at 55 CAD ATDC which might be expected, and likely to be due to both effect of continued oxidation (albeit at a reduced rate) and the absence of further PAH formation following near-complete fuel consumption. PAH species were extracted from surface of PM and much of the PM burns out during the tail end of combustion, so PM in the exhaust is much smaller relative to that in the engine cylinder ( as confirmed in Figure 2a) so exhaust PAH is consequently much smaller. Oxidation is a surface phenomenon and although a reduced oxidation rate is expected during late combustion phase relative to diffusion combustion phase due to lower global in-cylinder temperatures (Table 1), the exhaust valve opens much later, around 120 CAD after late combustion during which PAH species have more time to undergo oxidation

Figure $2 \mathrm{~b}$ shows that the gas-phase PAH is one order of magnitude higher that soot-bound PAH at 10 CAD ATDC while at the other sampling timings, both levels are of the same order of magnitude, though gas phase PAHs exceed those in the soot-bound phase at all the sampling timings. It can also be observed in Figure $2 b$ that the decrease in total PAH between 10 and 25 CAD ATDC seen earlier in Figure 2a was dominated by the reduction in the gas phase PAH. As combustion proceeded beyond 25 CAD ATDC, Figure $2 \mathrm{~b}$ shows that the total gas-phase and sootbound PAH mass continued to decrease, although at a much slower rate relative to the significant decrease during early diffusion-controlled combustion, reaching a minimum at 40 CAD ATDC and then increased almost four-fold and two-fold respectively at 55 CAD ATDC. It can be seen in Figure $2 \mathrm{~b}$ that the increase in total PAH level seen at 55 CAD ATDC is dominated by gaseous PAH, likely attributable to pyrolysis as fuel continued to be burned. Also, at 55 CAD ATDC which occurs during the expansion stroke, fuels previously unreacted coming off the cylinder wall crevices into the incylinder charge can become pyrolyzed and form new PAH species. Additionally, although, a significant amount of the fuel (95\%) has been burnt at 55 CAD ATDC as evidenced in Figure S $3 a$ and in-cylinder temperature at this time is $1277.6 \mathrm{~K}$ (Table 1), the remaining $5 \%$ of the fuel yet to release useful energy will likely also undergo pyrolysis under these conditions, thus, creating additional PAH species. During the interval between 55 CAD ATDC and engine exhaust, gas-phase and soot-bound PAHs decreased by $99.62 \%$ and $99.13 \%$ respectively. In general, Figure $2 \mathrm{~b}$ shows that when PAH levels increase or decrease, the proportion of gas phase PAHs affected significantly exceeds that of soot-bound PAHs.

\subsubsection{Changes in the abundance of total gas-phase and soot-bound PAH species during combustion from premixed to exhaust}

Figure $3 a$ shows that the substantial decrease in gas phase PAH species seen in Figure $2 b$ between 10 and 25 CAD ATDC can primarily be attributed to a significant decrease in 2- and 3ring gas-phase PAH species. Of all soot-bound PAH species, 4-ring PAH species decreased the most between 10 to 25 CAD ATDC, likely indicating greater rates of consumption to soot particles or growth to larger PAHs than formation and adsorption onto soot particles. The overall reduction seen in soot-bound PAH species on a per volume basis apparent in Figure $3 a$ is in agreement with the reduction in PM mass between 10 CAD and 25 CAD ATDC seen in Figure 2a, but it is interesting to note that the reduction is not uniform across all PAH sizes.

Figure 3b shows a decrease in 3-ring PAH species between 25 CAD and 40 CAD ATDC with a more significant reduction in the gas-phase than in the soot-bound phase and a concurrent increase in 4-ring soot-bound PAH species. Figure $3 \mathrm{~b}$ also shows relatively small increases in the levels of 
smaller gaseous 2-ring PAH and larger soot-bound 4- and 6-ring PAH $\left(<100 \mu \mathrm{g} / \mathrm{m}^{3}\right)$. It is suggested therefore that significant levels of growth from 3-ring PAHs to larger species at reaction rates higher than those for the formation of 3-ring PAH may occur during this period.

Figure 3c shows a significant increase in 2- \& 3-ring gas-phase PAH species and 4-ring soot-bound PAH species between 40 CAD and 55 CAD ATDC. The much more significant increase in the smaller gas-phase PAH suggests presence in the in-cylinder sampling volume of previously unreacted fuel during cylinder-gas expansion, possibly due either to in-cylinder air motion and swirl or the release of fuel impinged on cylinder walls. It is hypothesised that the absence of a concurrent significant increase in PM (Figure 2a) or larger 5- and 6-ring PAH (Figure 3c) suggests the breakdown of the previously unreacted fuel to have not commenced significantly before sampling at 55 CAD ATDC. Figure 3d shows a substantial decrease in all PAH species between 55 CAD ATDC and the exhaust, especially 2- and 3-ring PAH species present in the gas phase, suggesting a cessation of PAH formation in addition to continued oxidation.

It is tentatively suggested that the much greater reduction in gaseous 2- and 3-ring PAH species (Figure $3 a$ ) can be attributed to a combination of the following reasons:

- PAH oxidation

- fuel PAH consumption

- consumption of these species through growth to larger PAH species

- reduced availability of precursors for the formation of the first ring (benzene) with a greater fuel mass fraction burnt relative to the period between the start of combustion at TDC and 10 CAD ATDC (Figure S 3a).

\subsubsection{Changes in the abundance of each individual PAH species during combustion in the engine cylinder}

Figure $4 a$ confirms that the majority of the decrease found in the 3-ring PAH species (Figure 3a) between 10 CAD and 25 CAD ATDC is due to a decrease in acenaphthylene. The presence of acenaphthylene is significant as it was shown by Shukla and Koshi (47) that it is possible for acenaphthylene to form higher molecular-weight PAH species via the HACA mechanism. Figure $4 \mathrm{~b}$ and Figure $4 \mathrm{c}$ show that the level of pyrene (PYR) present at 10 CAD ATDC was significantly higher than those of the other 4-ring PAH (fluoranthene, FLT; benzo[a]anthracene, $\mathrm{B}[\mathrm{a}] \mathrm{A}$; and chrysene, $\mathrm{CHR}$ ), and the decrease in the level of pyrene from 10 to 25 CAD ATDC is also the highest. Appel J, Bockhorn H, Frenklach M (48) noted that previous soot modelling studies represented the soot particle nucleation process as collisions between pyrene and larger PAH species, suggesting pyrene may more readily contribute to PM formation than smaller PAH. Figure 4c and d show that the level of D[ah]A (5-ring PAH) at 10 CAD ATDC was the smallest relative to other PAH of the same size $(B[b] F, B[k] F$ and $B[a] P)$. The benzene rings in $D[a h] A$ join together to form a chain which is different from the clustered structure of the other 5-ring PAH species. The significantly lower level of $D[a h] A$ could therefore suggest preferential PAH growth to PAH species with clustered benzene rings. Figure $4 \mathrm{c}$ and $\mathrm{d}$ show a higher proportional increase in 5- and 6-ring PAH levels at 55 CAD relative to 40 CAD ATDC except for dibenz[ah]anthracene; thus, suggesting that in-cylinder conditions seem to favour the persistence of closely-clustered high molecular-weight PAHs later on during combustion.

4.1.4.1. $B[a] P$ equivalence of particulate matter during the course of combustion The $\mathrm{B}[\mathrm{a}] \mathrm{P}$ equivalence of particulate matter indicates the level of its toxicity and was calculated using Equation 2.2. Readily apparent from Figure $4 e$ is the increase in both $P M B[a] P$ equivalence and soot-bound PAH in the engine cylinder, following a decrease earlier at 25 CAD ATDC. The increase in PM B[a]P equivalence is primarily attributable to an increase in the abundance of soot-bound PAH species, especially larger ones belonging to the B2 group whose TEF is relatively high. Thereafter, in the period between 40 CAD and 55 CAD ATDC, continuing combustion resulted in increased levels of toxic PAH species bound onto PM, despite an only slight increase in total soot-bound $\mathrm{PAH}$, and can be attributed to a significant increase in B[a]P and $\mathrm{D}[\mathrm{ah}] \mathrm{A}$ during this period (Figure $4 \mathrm{~d}$ ). 
Between 25 CAD and 40 CAD a decrease in the level of phenanthrene concurred with an increase in the levels of both pyrene and benzo[ghi]perylene (see Figure $S$ 11a for graphical representation). Shukla and Koshi (49) studied possible precursors to major pyrolysis products of benzene, acetylene $\left(\mathrm{C}_{2} \mathrm{H}_{2}\right)$ and a mixture of benzene and acetylene in a flow tube reactor and they suggested that benzo[e]pyrene $(B[e] P)$ yields benzo[ghi]perylene $(B[g h i] P)$ via the HACA mechanism. Although, $\mathrm{B}[\mathrm{e}] \mathrm{P}$ was not measured in this study, it is therefore cautiously suggested that the growth of phenanthrene to B[ghi]P (Figure $S$ 9) may have occurred into two stages:

1. Phenanthrene to $B[e] P$ via Phenyl Addition Cyclisation (PAC mechanism)

2. $B[e] P$ to $B[$ ghi $] P$ via the HACA mechanism

Acetylene is a well-known key PAH precursor and its likely involvement in the formation of both pyrene and benzo[ghi]perylene suggests that it is a possible pyrolysis product of fossil diesel. For instance, Ciajolo A, D'Anna A, Barbella R, Bertoli C (24) found acetylene to be one of the major pyrolysis products in the combustion of tetradecane (a diesel-fuel surrogate) and several soot modelling studies include the pyrolytic production of acetylene as one of the steps in the soot formation process (50), (51), (52). Also apparent during this period, is a decrease in the level of benzo[b]fluoranthene concurred with a greater increase in the level of indeno[123-cd]pyrene (I[123-cd]P) (see Figure S 11b). Shukla and Koshi (47) also suggested that phenylpyrene (phenyl addition to pyrene) is a precursor to the formation of indeno[123-cd]pyrene; this is a possibility given the apparent availability of pyrene and the possibility of the presence of benzene among the pyrolytic products of fossil diesel as suggested by Xanthopoulou (53). It is cautiously suggested that abstraction of two hydrogen atoms from benzo[b]fluoranthene $\left(\mathrm{C}_{20} \mathrm{H}_{12}\right)$ and subsequent addition of acetylene via HACA () could have also contributed to the formation of a greater amount of indeno[123-cd]pyrene $\left(\mathrm{C}_{22} \mathrm{H}_{12}\right)$, in addition to formation via phenylpyrene.

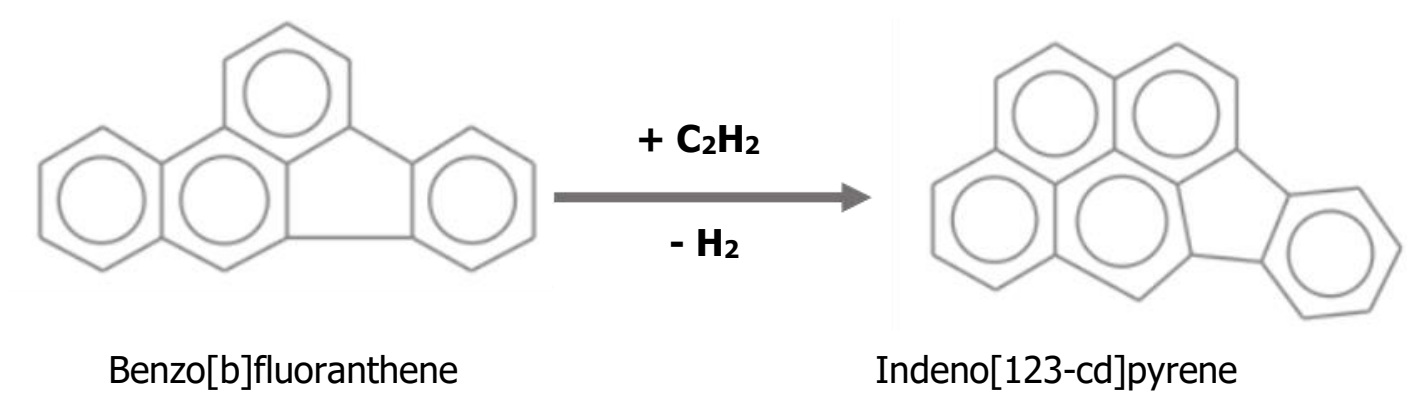

Figure 5: Growth of benzo[b]fluoranthene to Indeno[123-cd]pyrene via HACA mechanism

Exhaust PAH was composed mainly of 2- and 3-ring PAH species predominantly present in the gaseous phase which can increase the toxicity of ambient air to humans. There is evidence in this study that PAH levels reduced, and PM burned out as in-cylinder temperature increased during diffusion combustion while during late combustion when temperature fell, PAH levels rise, including the B2 group PAH. Therefore, a practical implication is to consider design that improves and enhances oxidation and high temperature towards end of combustion to limit PAH rise and consequently further reduce exhaust PAH levels. An environmental implication is that a further reduction in PAH levels during late combustion will further reduce exhaust levels of B2-group PAH and consequently the toxicity of exhaust gas. However, any such combustion strategy to reduce late combustion formation and accumulation of PAH should also consider the potential effects on thermal efficiency and NOx emissions, and thus further impacts on GHG and air quality emissions, respectively. 
Acknowledgement/Funding sources: This work is supported by both the Nigerian Petroleum 545 Technology Development Fund (PTDF) and the UK Engineering and Physical Sciences Research 546 Council (EPSRC grant:EP/M007960/1).

Supporting information

549 The 16 EPA priority PAH species measured in this study, Schematic diagram and diesel engine specifications, In-cylinder gas sampling valve description, Fossil diesel fuel properties, Description of the Accelerated solvent extraction and optimised extraction conditions, GCMS configuration, PAH assignment to deuterated PAH species, In-cylinder conditions and sampling timings, Measured concentrations of exhaust PM and PAH, PAH speciation according to the number of benzene rings during combustion, Change in the abundance of total gas-phase and soot-bound PAH species during combustion from premixed to exhaust, Potential PAH growth mechanisms in diesel combustion.

${ }^{*}$ Corresponding author : Christopher Chinedu Ogbunuzor

561

E-mail : ucemcog@ucl.ac.uk, Tel : +44-74-2955-3453.

562

Postal address: 42 Stockton Road, Reigate, Surrey, RH2 8JG 
1. Richter H, Howard JB. Formation of polycyclic aromatic hydrocarbons and their growth to soot-a review of chemical reaction pathways. Progress in Energy and Combustion Science. 2000 Aug 1;26(4):565-608. 2. Sprouse C, Depcik C. Review of organic Rankine cycles for internal combustion engine
exhaust waste heat recovery. Applied Thermal Engineering. 2013 Mar 1;51(1):711-22.

3. Yue T, Gao X, Gao J, Tong Y, Wang K, Zuo P, Zhang X, Tong L, Wang C, Xue Y. Emission characteristics of NOx, CO, NH3 and VOCs from gas-fired industrial boilers based on field measurements in Beijing city, China. Atmospheric Environment. 2018 Jul 1;184:1-8.

4. Mau V, Gross A. Energy conversion and gas emissions from production and combustion of poultry-litter-derived hydrochar and biochar. Applied Energy. 2018 Mar 1;213:510-9.

5. Han F, Guo H, Hu J, Zhang J, Ying Q, Zhang H. Sources and health risks of ambient polycyclic aromatic hydrocarbons in China. Science of The Total Environment. 2020 Jan 1;698:134229.

6. Strandberg $B$, Julander $A$, Sjöström $M$, Lewné $M$, Hatice $K A$, Bigert $C$. An improved method for determining dermal exposure to polycyclic aromatic hydrocarbons. Chemosphere. 2018 May 1;198:274-80.

7. Hoppe-Jones C, Beitel S, Burgess JL, Snyder S, Flahr L, Griffin S, Littau S, Jeong KS, Zhou J, Gulotta J, Moore P. Use of urinary biomarkers and bioassays to evaluate chemical exposure and activation of cancer pathways in firefighters. Occup Environ Med. $2018 \mathrm{Apr}$ 1;75(Suppl 2):A412-3.

8. Mayer AC, Fent KW, Bertke S, Horn GP, Smith DL, Kerber S, La Guardia MJ. Firefighter hood contamination: Efficiency of laundering to remove PAHs and FRs. Journal of Occupational and Environmental Hygiene. 2018 Nov 14;1-32.

9. Chen A, Northcross A, Folger S. Environmental Degradation in Baía de Todos os Santos, Brazil: A Review of the Evidence. 2018;

10. Geier MC, Chlebowski AC, Truong L, Massey Simonich SL, Anderson KA, Tanguay RL. Comparative developmental toxicity of a comprehensive suite of polycyclic aromatic hydrocarbons. Arch Toxicol. 2018 Feb 1;92(2):571-86.

11. Ballesteros R, Hernández JJ, Lyons LL. An experimental study of the influence of biofuel origin on particle-associated PAH emissions. Atmospheric Environment. 2010 Mar $1 ; 44(7): 930-8$.

12. Nadal $M$, Schuhmacher $M$, Domingo JL. Levels of PAHs in soil and vegetation samples from Tarragona County, Spain. Environmental Pollution. 2004 Nov 1;132(1):1-11.

13. Keith LH. The source of US EPA's sixteen PAH priority pollutants. Polycyclic Aromatic Compounds. 2015;35(2-4):147-160. 
14. He C, Ge Y, Tan J, You K, Han X, Wang J. Characteristics of polycyclic aromatic hydrocarbons emissions of diesel engine fueled with biodiesel and diesel. Fuel. 2010 Aug;89(8):2040-6.

15. Tsai J-H, Chen S-J, Huang K-L, Lin Y-C, Lee W-J, Lin C-C, Lin W-Y. PM, carbon, and PAH emissions from a diesel generator fuelled with soy-biodiesel blends. Journal of Hazardous Materials. 2010 Jul 15;179(1):237-43.

16. Tsai J-H, Chen S-J, Huang K-L, Lee W-J, Kuo W-C, Lin W-Y. Characteristics of particulate emissions from a diesel generator fueled with varying blends of biodiesel and fossil diesel. Journal of Environmental Science and Health, Part A. 2011 Jan 1;46(2):204-13.

17. Borrás E, Tortajada-Genaro LA, Vázquez M, Zielinska B. Polycyclic aromatic hydrocarbon exhaust emissions from different reformulated diesel fuels and engine operating conditions. Atmospheric Environment. 2009 Dec 1;43(37):5944-52.

18. How HG, Teoh YH, Masjuki HH, Kalam MA. Impact of coconut oil blends on particulatephase PAHs and regulated emissions from a light duty diesel engine. Energy. 2012 Dec $1 ; 48(1): 500-9$.

19. Lin $\mathrm{Y}-\mathrm{C}$, Lee $\mathrm{W}-\mathrm{J}$, Hou H-C. PAH emissions and energy efficiency of palm-biodiesel blends fueled on diesel generator. Atmospheric Environment. 2006 Jul 1;40(21):3930-40.

20. Barbella R, Bertoli C, Ciajolo A, D'anna A. Behavior of a fuel oil during the combustion cycle of a direct injection diesel engine. Combustion and Flame. 1990 Nov 1;82(2):1918.

21. Malmborg VB, Eriksson AC, Shen M, Nilsson P, Gallo Y, Waldheim B, Martinsson J. Evolution of In-Cylinder Diesel Engine Soot and Emission Characteristics Investigated with Online Aerosol Mass Spectrometry. Environmental Science \& Technology. 2017 Feb 7;51(3):1876-85.

22. Wang X, Song C, Lv G, Song J, Li H, Li B. Evolution of in-cylinder polycyclic aromatic hydrocarbons in a diesel engine fueled with $n$-heptane and $n$-heptane/toluene. Fuel. 2015 Oct 15;158:322-9.

23. Narushima T, Morishima A, Moriwaki H, Kusaka J, Daisho Y. Experimental and Numerical Studies on Soot Formation in Fuel Rich Mixture [Internet]. Warrendale, PA: SAE International; 2003 May [cited 2018 Dec 5]. Report No.: 2003-01-1850. Available from: https://www.sae.org/publications/technical-papers/content/2003-01-1850/

24. Ciajolo A, D'Anna A, Barbella R, Bertoli C. Combustion of Tetradecane and Tetradecane/ a-Methylnaphthalene in a Diesel Engine with Regard to Soot and PAH Formation. Combustion Science and Technology. 1993 Jan;87(1-6):127-37.

25. Kang I, Bae J, Bae G. Performance comparison of autothermal reforming for liquid hydrocarbons, gasoline and diesel for fuel cell applications. Journal of Power Sources. 2006 Dec 7;163(1):538-46.

26. Aakko P, Harju T, Niemi M, Rantanen-Kolehmainen L. PAH content of diesel fuel and automotive emissions. VTT Technical Research Centre of Finland Research Report VTT. 2006; 
27. Tree DR, Svensson KI. Soot processes in compression ignition engines. Progress in Energy and Combustion Science. 2007 Jun 1;33(3):272-309.

28. Talibi M, Hellier P, Balachandran R, Ladommatos N. Development of a fast-acting, timeresolved gas sampling system for combustion and fuels analysis. SAE International Journal of Engines. 2016;9(2):1102-1116.

29. US EPA. Compendium of Methods for the Determination of Toxic Organic Compounds in Ambient Air. Environmental Protection Agency, US Federal Register, Compendium Method TO-13A 1-42 [Internet]. 1999 [cited 2018 Apr 6]. Available from: https://www3.epa.gov/ttn/amtic/files/ambient/airtox/to-13arr.pdf

30. Dandajeh HA, Ladommatos $\mathrm{N}$, Hellier $\mathrm{P}$, Eveleigh A. Effects of unsaturation of $\mathrm{C} 2$ and $\mathrm{C} 3$ hydrocarbons on the formation of PAHs and on the toxicity of soot particles. Fuel. 2017 Apr 15;194:306-20.

31. Sánchez NE, Callejas A, Millera A, Bilbao R, Alzueta MU. Formation of PAH and soot during acetylene pyrolysis at different gas residence times and reaction temperatures. Energy. 2012 Jul 1;43(1):30-6.

32. Karavalakis G, Boutsika V, Stournas S, Bakeas E. Biodiesel emissions profile in modern diesel vehicles. Part 2: Effect of biodiesel origin on carbonyl, PAH, nitro-PAH and oxyPAH emissions. Science of The Total Environment. 2011 Jan 15;409(4):738-47.

33. Karavalakis G, Bakeas E, Fontaras G, Stournas S. Effect of biodiesel origin on regulated and particle-bound PAH (polycyclic aromatic hydrocarbon) emissions from a Euro 4 passenger car. Energy. 2011 Aug 1;36(8):5328-37.

34. Dandajeh HA, Ladommatos $\mathrm{N}$, Hellier $\mathrm{P}$, Eveleigh A. Influence of carbon number of $\mathrm{C1-}$ C7 hydrocarbons on PAH formation. Fuel. 2018 Sep 15;228:140-51.

35. Park SS, Kim YJ, Kang CH. Atmospheric polycyclic aromatic hydrocarbons in Seoul, Korea. Atmospheric Environment. 2002 Jun 1;36(17):2917-24.

36. Kanaujia PK, Singh D, Tripathi D, Konathala LNSK, Saran S, Chauhan RK, Sharma YK, Garg MO. Characterization and Identification of Polycyclic Aromatic Hydrocarbons in Diesel Particulate Matter. Analytical Letters. 2015 Sep 22;48(14):2303-18.

37. Nisbet ICT, LaGoy PK. Toxic equivalency factors (TEFs) for polycyclic aromatic hydrocarbons (PAHs). Regulatory Toxicology and Pharmacology. 1992 Dec 1;16(3):290300.

38. Dec JE. Advanced compression-ignition engines-understanding the in-cylinder processes. Proceedings of the Combustion Institute. 2009;32(2):2727-42.

39. Indarto A, Ghigo G, Maranzana A, Tonachini G. Polycyclic aromatic hydrocarbon formation mechanism in the 'particle phase'. A theoretical study. Physical chemistry chemical physics: PCCP. 2010 Aug 28;12:9429-40.

40. Duggal VK, Priede T, Khan IM. A Study of Pollutant Formation within the Combustion Space of a Diesel Engine. SAE Transactions. 1978;87:987-1000. 
41. Li Z, Song C, Song J, Lv G, Dong S, Zhao Z. Evolution of the nanostructure, fractal dimension and size of in-cylinder soot during diesel combustion process. Combustion and Flame. 2011 Aug 1;158(8):1624-30.

42. Aoyagi Y, Kamimoto T, Matsui Y, Matsuoka S. A Gas Sampling Study on the Formation Processes of Soot and NO in a DI Diesel Engine. SAE Transactions. 1980;89:1175-89.

43. Dec JE. A Conceptual Model of DI Diesel Combustion Based on Laser-Sheet Imaging* [Internet]. Warrendale, PA: SAE International; 1997 Feb [cited 2018 Feb 19]. Report No.: 970873. Available from: http://papers.sae.org/970873/

44. Hiroyasu $H$, Arai M, Nakanishi K. Soot Formation and Oxidation in Diesel Engines. SAE Transactions. 1980;89:1148-62.

45. Talibi M. Co-combustion of diesel and gaseous fuels with exhaust emissions analysis and in-cylinder gas sampling [Internet] [Doctoral]. UCL (University College London); 2015 [cited 2019 May 1]. Available from: http://discovery.ucl.ac.uk/1471760/

46. Barbella R, Bertoli C, Ciajolo A, D'Anna A, Masi S. In-Cylinder Sampling of High Molecular weight Hydrocarbons From a D.I. Light Duty Diesel Engine. SAE Transactions. 1989;98:712-21.

47. Shukla B, Koshi M. A novel route for PAH growth in HACA based mechanisms. Combustion and Flame. 2012 Dec 1;159(12):3589-96.

48. Appel J, Bockhorn $H$, Frenklach M. Kinetic modeling of soot formation with detailed chemistry and physics: laminar premixed flames of $\mathrm{C} 2$ hydrocarbons. Combustion and Flame. 2000 Apr 1;121(1):122-36.

49. Shukla B, Koshi M. A highly efficient growth mechanism of polycyclic aromatic hydrocarbons. Physical Chemistry Chemical Physics. 2010;12(10):2427.

50. Belardini P, Bertoli C, Del Giacomo N, Iorio B. Soot formation and oxidation in a di diesel engine: A comparison between measurements and three dimensional computations. In: Fall Fuels and Lubricants Meeting and Exposition, October 18, 1993 - October 21, 1993. SAE International; 1993. (SAE Technical Papers).

51. Sung N, Lee S, Kim H, Kim B. A numerical study on soot formation and oxidation for a direct injection diesel engine. Proceedings of the Institution of Mechanical Engineers, Part D: Journal of Automobile Engineering. 2003 May 1;217(5):403-13.

52. Cheng X, Chen L, Yan F, Dong S. Study on soot formation characteristics in the diesel combustion process based on an improved detailed soot model. Energy Conversion and Management. 2013;75:1-10.

53. Xanthopoulou G. Oxide catalysts for pyrolysis of diesel fuel made by self-propagating high-temperature synthesis. Part I: cobalt-modified Mg-Al spinel catalysts. Applied Catalysis A: General. 1999 Jun 21;182(2):285-95.

54. Kim K-H, Jahan SA, Kabir E, Brown RJC. A review of airborne polycyclic aromatic hydrocarbons (PAHs) and their human health effects. Environment International. 2013 Oct;60:71-80. 
55. Karabektas M, Hosoz M. Performance and emission characteristics of a diesel engine using isobutanol-diesel fuel blends. Renewable Energy. 2009 Jun 1;34(6):1554-9.

56. Lu T, Cheung CS, Huang Z. Effects of engine operating conditions on the size and nanostructure of diesel particles. Journal of Aerosol Science. 2012 May 1;47:27-38.

57. Corrêa SM, Arbilla G. Aromatic hydrocarbons emissions in diesel and biodiesel exhaust. Atmospheric Environment. 2006 Nov 1;40(35):6821-6.

58. Barbella R, Bertoli C, Ciajolo A, D'anna A. Soot and Unburnt Liquid Hydrocarbon Emissions from Diesel Engines. Combustion Science and Technology. 1988 May 1;59(13):183-98.

59. Tavares M, Pinto JP, Souza AL, Scarmínio IS, Cristina Solci M. Emission of polycyclic aromatic hydrocarbons from diesel engine in a bus station, Londrina, Brazil. Atmospheric Environment. 2004 Sep 1;38(30):5039-44.

60. Marr LC, Kirchstetter TW, Harley RA, Miguel AH, Hering SV, Hammond SK. Characterization of Polycyclic Aromatic Hydrocarbons in Motor Vehicle Fuels and Exhaust Emissions. Environmental Science \& Technology. 1999 Sep;33(18):3091-9.

61. Zielinska B, Sagebiel J, Arnott WP, Rogers CF, Kelly KE, Wagner DA, Lighty JS, Sarofim AF, Palmer G. Phase and Size Distribution of Polycyclic Aromatic Hydrocarbons in Diesel and Gasoline Vehicle Emissions. Environmental Science \& Technology. 2004 May;38(9):2557-67.

62. Sánchez NE, Callejas A, Millera Á, Bilbao R, Alzueta MU. Polycyclic Aromatic Hydrocarbon $(\mathrm{PAH})$ and Soot Formation in the Pyrolysis of Acetylene and Ethylene: Effect of the Reaction Temperature. Energy \& Fuels. 2012 Aug 16;26(8):4823-9.

63. Tancell PJ, Rhead MM, Pemberton RD, Braven Jim. Survival of Polycyclic Aromatic Hydrocarbons during Diesel Combustion. Environmental Science \& Technology. 1995 Nov;29(11):2871-6.

64. Williams PT, Bartle KD, Andrews GE. The relation between polycyclic aromatic compounds in diesel fuels and exhaust particulates. Fuel. 1986 Aug 1;65(8):1150-8.

65. Williams PT, Abbass MK, Andrews GE, Bartle KD. Diesel particulate emissions: The role of unburned fuel. Combustion and Flame. 1989 Jan 1;75(1):1-24.

66. Rhead MM, Pemberton RD. Sources of Naphthalene in Diesel Exhaust Emissions. Energy \& Fuels. 1996 Jan;10(3):837-43.

67. Kislov W, Sadovnikov AI, Mebel AM. Formation Mechanism of Polycyclic Aromatic Hydrocarbons beyond the Second Aromatic Ring. J Phys Chem A. 2013 Jun $13 ; 117(23): 4794-816$.

68. Dobbins RA, Fletcher RA, Benner BA, Hoeft S. Polycyclic aromatic hydrocarbons in flames, in diesel fuels, and in diesel emissions. Combustion and Flame. 2006 Mar 1;144(4):77381. 